\title{
Vigor de sementes de coentro (Coriandrum sativum L.) provenientes de sistemas orgânico e convencional
}

\author{
SILVA, M.A.D.*; COELHO JÚNIOR, L.F.; SANTOS, A.P. \\ Universidade Federal Rural de Pernambuco (UFRPE) - Unidade Acadêmica de Serra Talhada (UAST), Fazenda \\ Saco, s/n. Caixa postal 063, CEP: 56.900-000,Serra Talhada-Brasil *monallyysa@yahoo.com.br
}

\begin{abstract}
RESUMO: O coentro (Coriandrum sativum L.) é uma hortaliça amplamente consumida no Brasil como condimento. É muito importante, especialmente para a horticultura do Norte e Nordeste do Brasil. É provável que, em relação ao valor de mercado, seja a segunda hortaliça folhosa em importância para o Brasil, com grande volume de importação e produção nacional de sementes. Problemas relacionados ao baixo vigor das sementes e ao estabelecimento da cultura são uma constante nesta espécie. O presente trabalho teve como objetivo verificar a influência do sistema de produção orgânico e convencional sobre o potencial fisiológico das sementes de coentro. Foram avaliados lotes de sementes de coentro, cultivar Verdão, provenientes de sistemas de cultivo convencional e orgânico. $O$ delineamento experimental foi inteiramente casualizado com seis tratamentos e quatro repetições de cinqüenta sementes. Foram avaliados o grau de umidade, porcentagem de emergência, primeira contagem do teste de emergência, peso de mil sementes, índice de velocidade de emergência de plântulas e teste de condutividade. As avaliações realizadas mostraram que os sistemas de cultivo de modo geral não diferem entre si quanto ao potencial fisiológico das sementes.
\end{abstract}

Palavras-chave: Coriandrum sativum L., potencial fisiológico, sistemas de cultivo

\begin{abstract}
Evaluation of force of coriander (Coriandrum sativum L.) seeds from the organic and conventional systems. The coriander (Coriandum sativum L.) is an herb widely consumed in Brazil as a condiment. It is very important, particularly for horticulture in North and Northeast of Brazil. IT is likely that, in terms of market value, it is the second herb hardwood dusts in importance for Brazil, losing only to the lettuce and the high volume of imports and domestic production of seed. Problems related to the low seed vigor and the establishment of culture are a constant in this species. In the present work lots of coriander seeds, the cv. Verdão, from systems of conventional and organic were evaluated, having as objective is to verify the influence of the physiological potential of the seeds on the initial development of plants grown under organic system. They were evaluated degree of humidity, percentage of emergency, first count of the test of emergency, weight of 1,000 seeds, index of emergency speed of seedlings and conductivity test. The experimental design was a completely randomized design with four replicates of 50 seeds. The assessments carried out showed that the cultivation systems in general does not differ as to the physiological potential of the seeds.
\end{abstract}

Key words: Coriandrum sativum L., physiological potential, cultivation

\section{INTRODUÇÃO}

O coentro (Coriandrum sativum L.) é uma hortaliça herbácea anual pertencente à família Apiaceae, nativa da bacia do Mar Mediterrâneo (Joly, 2002). Apesar de ser considerada uma cultura de "fundo de quintal", grande número de produtores está envolvido com a produção, tornando-se uma cultura de grande importância socioeconômica; especialmente para a horticultura do Norte e Nordeste do país. Possui um alto valor de mercado, ficando atrás apenas da alface em importação e produção nacional.

De acordo com Melo et al. (2003), as folhas de coentro no Brasil são muito utilizadas como tempero na culinária, especialmente na região nordeste. Desde a antiguidade, principalmente na

Recebido para publicação: setembro de 2011

Aceito para publicação: março de 2012

Rev. Bras. Pl. Med., Botucatu, v.14, n.esp., p.192-196, 2012. 
região do mediterrâneo e leste europeu, há registros da utilização medicinal (Ishikawa et al., 2003). Tanto os frutos como as folhas do coentro apresentam propriedades estomáquicas e carminativas, sendo que em Farmacopéias Européias há o registro do fruto para tais finalidades (Costa, 2002). Ainda, o coentro é utilizado como antipirético, anti-helmíntico e analgésico no tratamento de dores articulares e reumatismo (Ishikawa et al., 2003). O óleo essencial do fruto é empregado na perfumaria, em preparações farmacêuticas como flavorizante e edulcorante em medicamentos e bebidas alcoólicas (Costa, 2002). São diversas as pesquisas que mostram que o coentro apresenta atividades como hipolipemiante (Chithra \& Leelamma, 1997), antimicrobiana (Lo Cantore et al., 2004), hipoglicemiante (Gray \& Flatt, 1999; Eidi et al., 2009), anti-hipertensiva e diurética (Jabeen et al., 2009).

Nas regiões Norte e Nordeste do Brasil são encontradas condições favoráveis no que se diz respeito ao clima, possibilitando o cultivo durante o ano todo. $O$ diaquênio do coentro é um fruto-semente que é constituído de dois aquênios, sendo geralmente comercializado inteiro.

A alta qualidade de sementes de hortaliças é de grande importância, principalmente quanto à germinação uniforme, necessária para garantir um estande ideal de plantas. Neste contexto, sementes de alto vigor se constituem em elemento básico e fundamental (Mendonça et al., 2003).

Estudos realizados por Marcos Filho \& Kikuti (2006) em sementes de rabanete avaliando a influência do vigor de diferentes lotes das cultivares, Gigante Siculo e Cometa, sobre o comportamento das plantas em campo mostraram que para ambas as cultivares houve relação entre o vigor das sementes e o desenvolvimento inicial das plantas, mas não foi verificado o mesmo para a produção final.

Ao relacionar o potencial fisiológico de sementes de couve flor e o desempenho das plantas em casa de vegetação e em campo, Kikuti \& Marcos Filho (2007) concluíram que o nível de vigor das sementes de couve flor influenciou o desenvolvimento inicial das plantas, quando as diferenças entre o potencial fisiológico dos lotes foram acentuadas, mas esse efeito não persistiu em fases mais avançadas da cultura.

Dantas \& Torres (2010), ao observarem a relação do potencial fisiológico de sementes de rúcula e o desempenho das plantas em campo, constataram que variações estreitas do vigor de lotes de sementes de rúcula com germinação superior à mínima estabelecida para comercialização não são suficientes para influenciar significativamente o desempenho das plantas em campo sob condições favoráveis.

Rodrigues et al. (2007), ao realizarem estudo sobre os sistemas de produção de semente de cebola convencional e agroecológico observaram que a produção de semente de cebola através do sistema agroecológico é economicamente viável e ecologicamente sustentável. Neste mesmo trabalho os autores verificaram que o potencial de produção e qualidade fisiológica da semente de cebola agroecológica e convencional foram similares.

A produção nacional de sementes está ligada diretamente ao sistema convencional, mas isso vem mudando ao logo dos anos. Com as diversas transformações que o meio ambiente vem sofrendo, seja ela natural ou pela ação do homem, e da crise socioeconômica tem-se buscado à adaptação as novas tecnologias que preservem os recursos naturais existentes no meio em que vivemos. Para Ghini \& Bettiol (2000) esse enfoque altera as propriedades com sistemas convencionais de agricultura em relação ao uso de fontes não renováveis mudando a relação entre produção de alimentos e os impactos ambientais, essas alterações implicam na redução da dependência de produtos químicos e o maior uso de processos biológicos nos sistemas agrícolas.

Dentro desse contexto vem se destacando a produção de hortaliças, sendo bem trabalhada pela agricultura orgânica, devido ao crescimento no setor agrícola vem ganhando força em diversos países, independente do desenvolvimento. No Brasil, a agricultura orgânica vem numa constante crescente, de acordo com Schiedeck (2002), o mercado de alimentos produzidos sob a orientação agroecológica, sem utilização de agrotóxicos ou adubos minerais, tem aumentado em todo o mundo. Basta verificar o grande crescimento das feiras de produtos orgânicos que vem se espalhando por todo o país, além da entrada dos produtos orgânicos nas grandes redes de supermercados, e da conscientização dos consumidores que buscam alimentação mais saudável.

Poucos são os trabalhos relacionando o sistema de cultivo e a qualidade das sementes. Casaroli et al. (2006) verificaram que em sementes de abóbora, variedade Menina Brasileira, o maior potencial fisiológico foi observado nas sementes de origem convencional em relação à orgânica.

Mesmo com o crescimento do sistema orgânico dentro da agricultura não há muitas informações, referentes à produção de hortaliças neste tipo de sistema, principalmente quanto à origem da semente e vigor da mesma, justificando a relevância de estudos que abordem esses aspectos. Assim objetivou-se neste trabalho verificar a influência do potencial fisiológico das sementes de coentro, provenientes dos sistemas de cultivo orgânico e convencional.

\section{MATERIAL E MÉTODO}

Este experimento foi realizado nas dependências da Universidade Federal Rural de 
Pernambuco na Unidade Acadêmica de Serra Talhada, Serra Talhada - PE, Brasil.

As avaliações realizadas para se conhecer a qualidade das sementes de coentro (Coriandrum sativum L.), cv. Verdão foram:

a) Grau de umidade: foi realizado em estufa a $105 \pm 3^{\circ} \mathrm{C}$, durante 24 horas (Brasil, 2009), utilizandose duas amostras para cada lote de cada sistema de cultivo. Os resultados foram expressos em porcentagem.

b) Peso de 1000 sementes: foi realizado de acordo com as Regras para Análise de Sementes (Brasil, 2009).

c) Emergência de plântulas: foram utilizadas quatro repetições de 50 sementes semeadas em bandejas de poliestireno expandido (isopor) com células individuais, contendo como substrato mistura de solo e esterco bovino curtido na proporção de 1:1. As bandejas foram dispostas suspensas sobre uma bancada a 1,00 m do solo, sob sombrite com 50\% de sobreamento. Procedeu-se com duas irrigações diárias. As avaliações foram efetuadas por 21 dias, através da contagem diária das plântulas emergidas com as folhas cotiledonares expandidas.

d) Primeira contagem: foi conduzida conjuntamente com o teste de emergência, consistindo do registro da porcentagem de plântulas normais encontradas na primeira contagem ( 7 익 dia) do referido teste. Os resultados foram expressos em porcentagem média de plântulas normais.

e) Índice de velocidade: foi conduzido conjuntamente com o teste de emergência. Foram realizadas contagens diárias por período de tempo correspondente a última contagem, do número de plântulas emersas, obtendo-se o índice de velocidade de emergência (IVE). O cálculo do índice de velocidade foi conforme a fórmula de Maguire (1962).

f) Teste de condutividade elétrica: foi conduzido com quatro repetições de 50 sementes as quais foram pesadas com precisão de quatro casas decimais $(0,0001 \mathrm{~g})$ e colocadas para embeber (água destilada) em copos de plásticos com $75 \mathrm{~mL}$ por 24 horas. Após o condicionamento, a condutividade elétrica da solução foi medida em condutivímetro e os resultados expressos em $\mathrm{mS} \mathrm{cm}^{-1} \mathrm{~g}^{-1}$.

Foi utilizado o delineamento inteiramente casualizado, com dois sistemas de cultivo (orgânico e convencional) e três lotes para cada sistema de cultivo, perfazendo seis tratamentos com quatro repetições de 50 sementes. As médias obtidas foram comparadas pelo o teste de Scott-Knott, ao nível de $5 \%$ de probabilidade.

\section{RESULTADO E DISCUSSÃO}

A emergência de plântulas dos lotes utilizados nesta avaliação foi superior à mínima estabelecida (60\%) para comercialização de sementes de coentro (Brasil, 1985). De acordo com a Tabela 1, observa-se que no teste de emergência de plântulas, as sementes orgânicas e convencionais não apresentaram diferença significativa entre si. Ressalta-se, que as plântulas não foram expostas a condições ambientais adversas, pois as mesmas foram formadas sob sombrite com $50 \%$ de sobreamento, irrigadas duas vezes ao dia e durante a condução do experimento a temperatura média do ar e a umidade relativa foram $32,2^{\circ} \mathrm{C}$ e $64,4 \%$, respectivamente, o que contribuiu para 0 desenvolvimento das plântulas.

Verificou-se nas avaliações de primeira contagem e índice de velocidade de emergência, diferenças significativas referentes ao lote (1) das sementes orgânicas em relação aos demais. As sementes que germinam mais rapidamente, isto é, que apresentam maior porcentagem de plântulas normais nessa contagem, foram consideradas mais

TABELA 1. Resultados obtidos nos testes de emergência de plântulas (EP), primeira contagem (PC), índice de velocidade de emergência (IVE), peso de mil sementes (PMS), condutividade elétrica (CE), grau de umidade (GU), provenientes de sementes de coentro dos sistemas orgânicos $(\mathrm{O})$ e convencional,(C).

\begin{tabular}{lccccccc}
\hline $\begin{array}{c}\text { Sistema de } \\
\text { produção }\end{array}$ & Lotes & EP\% & PC \% & IVE & $\begin{array}{c}\text { Peso de 1000 } \\
\text { sementes }(\mathbf{g})\end{array}$ & $\begin{array}{c}\text { CE } \\
\left(\mu \text { Scm }^{-1} \mathbf{g}^{-1}\right)\end{array}$ & $\begin{array}{c}\text { Grau de } \\
\text { Unidade \% }\end{array}$ \\
\hline Comercial & 1 & $92,0 \mathrm{a}$ & $0,75 \mathrm{~b}$ & $4,908 \mathrm{~b}$ & $10,82 \mathrm{~b}$ & $896,00 \mathrm{~d}$ & 9,21 \\
& 2 & $92,50 \mathrm{a}$ & $2,50 \mathrm{~b}$ & $4,905 \mathrm{~b}$ & $10,69 \mathrm{~b}$ & $988,75 \mathrm{~d}$ & 9.45 \\
& 3 & $89,50 \mathrm{a}$ & $0,00 \mathrm{~b}$ & $4,423 \mathrm{~b}$ & $12,62 \mathrm{a}$ & $587,25 \mathrm{c}$ & 9.89 \\
Orgânico & 1 & $92,50 \mathrm{a}$ & $15,50 \mathrm{a}$ & $5,533 \mathrm{a}$ & $10,37 \mathrm{c}$ & $146,00 \mathrm{a}$ & 8,55 \\
& 2 & $95,50 \mathrm{a}$ & $0,50 \mathrm{~b}$ & $4,953 \mathrm{~b}$ & $12,55 \mathrm{a}$ & $342,50 \mathrm{~b}$ & 8,82 \\
& 3 & $95,50 \mathrm{a}$ & $0,00 \mathrm{~b}$ & $4,824 \mathrm{~b}$ & $12,53 \mathrm{a}$ & $699,50 \mathrm{c}$ & 7,89 \\
\hline CV \% & & 4,75 & 63,94 & 5,83 & 3,04 & 14,47 & \\
\hline
\end{tabular}

Letras distintas dentro de cada coluna diferem entre si, pelo teste de Scott-Knott a $5 \%$ de probabilidade. 
vigorosas. Na avaliação do peso de mil sementes, houve diferença significativa entre os sistemas, sendo que os lotes 1 e 2 do sistema orgânico e o lote 3 do sistema convencional foram superiores aos demais lotes. O teste de condutividade elétrica acusou a superioridade significativa do potencial fisiológico das sementes do lote 1 produzidas no sistema orgânico, em relação aos demais lotes tanto do sistema orgânico como do convencional, observação que pode estar relacionada com a primeira contagem das plântulas e ao índice de velocidade de emergência. Pesquisas com outras hortaliças, tais como cenoura (Andrade et al., 1995), pimentão (Panobianco \& Marcos Filho, 1998), brócolos (Mello et al., 1999) mostram a eficiência do teste de condutividade elétrica para avaliar o vigor das sementes. Na determinação do grau de umidade os lotes de sementes convencionais apresentaram teor de água um pouco maior que os lotes do sistema orgânico.

De maneira geral a qualidade inicial das sementes não foi influenciada pelos sistemas de cultivo, sendo que foi verificada pequena diferença de qualidade entre os lotes estudados, por sua vez Silva et al. (2005) observaram que as sementes de coentro provenientes do sistema orgânico tiveram um desempenho melhor do que as convencionais. Entretanto, Casaroli et al. ( 2006) verificaram que o maior potencial fisiológico foi nas sementes de origem convencional em relação à orgânica, assim como Silva et al. (2004) que constataram que as sementes de pepino provenientes do cultivo convencional apresentaram maior vigor do que aquelas de sistema orgânico.

Os efeitos do vigor das sementes sobre o desempenho das plantas podem ser evidentes no início do desenvolvimento, mas são reduzidos à medida que os estádios fenológicos se sucedem (Carvalho, 1986). Para TeKrony \& Egli (1991) a influência do vigor de sementes no estabelecimento do estande pode ser especialmente crítica para culturas que requerem distribuição espacial de plantas para maximizar o rendimento como alface, repolho, cebola e couve-flor. Salienta-se que o coentro também pode ser inserido dentro desse contexto. O fato é que a emergência atrasada ou "falhas" no estande podem reduzir a produção e a uniformidade das plantas por ocasião da colheita. Em alface (Franzin et al., 2003), brássicas (Powell et al. 1991), nabo (Lingegowda \& Andrews, 1973) e cebola (Rodo \& Marcos Filho, 2003) foram observados efeitos favoráveis do vigor sobre o desenvolvimento inicial das plantas, Larsen et al. (1998) salientam que mesmo na ausência de diferenças no estande inicial; o crescimento das plantas provenientes de sementes menos vigorosas pode ser mais demorado, podendo apresentar maior sensibilidade a condições ambientais adversas.
De modo geral o potencial fisiológico das sementes não é influenciado pelos sistemas de cultivo orgânico e convencional.

\section{REFERÊNCIA}

ANDRADE, R.N. et al. Correlação entre testes de vigor em sementes de cenoura armazenadas por diferentes períodos. Pesquisa Agropecuária Gaúcha, v.1, n.2, p.153-62, 1995.

BAJPAI, M.; MISHRA, A.; PAKASH, D. Antioxidant and free radical scavenging activities of some leafy vegetables. International Journal of Food Sciences and Nutrition, v.56, n.7, p.473-81, 2005.

BRASIL. Ministério da Agricultura, Pecuária e Abastecimento. Regras para análise de sementes / Ministério da Agricultura, Pecuária e Abastecimento. Secretaria de Defesa Agropecuária. Brasília : Mapa/ACS, 2009. 399p.

BRASIL. Portaria no 11, de 7 de janeiro de 1985 . (Estabelece os padrões de sementes olerícolas para produção, ...). Diário Oficial da União, Poder Executivo, Brasília, DF, p. 642, 9 jan. 1985.

CARVALHO, N.M. Vigor de sementes. In: MARCOS FILHO, J.; CICERO, S.M.; SILVA, W.R. (Eds.). Atualização em produção de sementes. Campinas: Fundação Cargill, 1986. p.207-23.

CASAROLI, D. et al. Qualidade sanitária e fisiológica de sementes de abóbora variedade Menina Brasileira. Fitopatologia Brasileira, v.31, p.158-63, 2006.

COSTA, A.F. Farmacognosia. 6.ed. Lisboa: Fundation Calouste Gulbenkian, 2002. 1031p.

DANTAS, M.R.S.; TORRES, S.B. Vigor de sementes de rúcula e desempenho das plantas em campo. Revista Brasileira de Sementes, v.32, p.49-57, 2010.

EIDI, M. et al. Effect of coriander seed (Coriandrum sativum L.) ethanol extract on insulin release from pancreatic beta cells in streptozotocin-induced diabetic rats. Phytotherapy Research, v.23, p.404-6, 2009.

FRANZIN, S.M. et al. Efeitos do vigor das sementes sobre a formação de mudas de alface. Informativo Abrates, v.13, n.3, p.305, 2003.

GHINI, R.; BETTIOL, W. Proteção de plantas na agricultora sustentável. Cadernos de Ciência \& Tecnologia, v.17, p.61-70, 2000.

GUERRA, N.B.; MELO, E.A.; MANCINI-FILHO, J. Antioxidant compounds from coriander (Coriandrum sativum) etheric extract. Journal of Food Composition and Analysis, v.18, p.193-9, 2005.

ISHIKAWA, T.; KONDO, K.; KITAJIMA, J. Water-soluble constituents of coriander. Chemical \& Pharmaceutical Bulletin, v.51, n.91, p.32-9, 2003.

JOLY, A.B. Botânica: introdução à taxonomia vegetal. São Paulo: Editora Nacional. 2002. 777p.

KIKUTI, A.L.P.; MARCOS FILHO, J. Potencial fisiológico de sementes de couve-flor e desempenho das plantas em campo. Revista Brasileira de Sementes, v.29, p.107-13, 2007.

LARSEN, S.U. et al. The influence of seed vigour on field performance and the evaluation of the applicability of the controlled deterioration vigour test in oil seed rape and pea. Seed Science and Technology, v.26, n.4, p.627-41, 1998. 
LINGEGOWDA, H.; ANDREWS, $\mathrm{H}$. Effects of seed size in cabbage and turnip on performance of seeds, seedlings and plants. Proceedings of the Association of Official Seed Analysts, v.63, p.117-25, 1973.

MAGUIRE, J.D. Speed of germination-aid in relation evaluation for seedling emergence vigor. Crop Science, v.2, n.1, p.176-7, 1962.

MARCOS FILHO, J.; CÍCERO, S.M.; SILVA, W.R. Avaliação da qualidade de sementes. Piracicaba: FEALQ, 1987. 230p.

MARCOS FILHO, J.; KIKUTI, A.L.P. Vigor de sementes de rabanete e desempenho de plantas no campo. Revista Brasileira de Sementes, v.28, p.44-51, 2006.

MELLO, S.C.; SPINOLA, M.C.M.; MINAMI, K. Métodos de avaliação da qualidade fisiológica de sementes de brócolos. Scientia Agricola, v.56, n.4, p.1151-5, 1999.

MELO, E.A. et al. Antioxidant activity of coriander extracts (Coriandrum sativum L.). Ciência e Tecnologia de Alimentos, v.23, p.195-9, 2003.

MENDONÇA, E.A.F.; RAMOS, N.P.; FESSEL, S.A. Adequação da metodologia do teste de deterioração controlada para sementes de brócolis (Brassica oleracea L. - Var.(Itálica). Revista Brasileira de Sementes, v.25, p.18-24, 2003.

PANOBIANCO, M.; MARCOS FILHO, J. Comparação entre métodos para avaliação da qualidade fisiológica de sementes de pimentão. Revista Brasileira de Sementes, v.20, n.2, p.306-10, 1998.

POWELL, A.A.; THORNTON, J.M.; MITCHELL, A. Vigour differences in brassica seed and their significance to emergence and seedling variability. Journal of Agricultural Science, v.116, n.3, p.369-73, 1991.

RODO, M.A.B.; MARCOS FILHO, J. Onion seed vigor in relation to plant growth and yield. Horticultura Brasileira, v.21, n.2, p.220-6, 2003.

RODRIGUES, A.P.D. et al. Produção de sementes de cebola em sistemas convencional e de transição agroecológica. Revista Brasileira de Sementes, v.28, p.87-97, 2007.

SATYANARAYANA, S. et al. Antioxidant activity of the aqueous extratcs of spicy food additives-evaliation and comparison with ascorbic acid in in vitro systems. Journal of Herbal Pharmacotherapy, v.4, n.2, p.1-10, 2004.

SCHIEDECK, G. Ambiência e resposta agronômica de meloeiro (Cucumis melo L.) cultivado sob adubação orgânica em ambiente protegido. 2002. 100p. Tese (Doutorado - área de Concentração em Agronomia) Faculdade de Agronomia, Pelotas.

SILVA, M.A.D. et al. Potencial fisiológico de sementes de pepino produzidas em dois sistemas de cultivo. In: CONGRESSO BRASILEIRO DE OLERICULTURA, 44. 2004, Campo Grande, Anais... Campo Grande: SOB, 2004. (CD-ROM).

SILVA, M.A.D. et al. Efeito do sistema de cultivo sobre o potencial fisiológico de sementes de coentro. In: CONGRESSO BRASILEIRO DE OLERICULTURA, 45. 2005, Fortaleza, Anais... Fortaleza: SOB, 2005. (CDROM).

TEKRONY, D.M.; EGLI, D.B. Relationship of seed vigor to crop yeld: a review. Crop Science, v.31, p.816-22, 1991. 